\title{
Las minas de Alquife en Granada
}

El complejo minero de Alquife constituye un ejemplo paradigmático de la dificultad de la salvaguarda del patrimonio industrial. El reconocimiento, a mediados del verano de 2010, de los valores patrimoniales del conjunto minero a través de su inscripción como Bien de Interés Cultural parecía augurar la conservación del ejemplo más relevante del patrimonio industrial minero granadino. Lamentablemente, el estado actual de abandono de las instalaciones está acelerando el proceso de su desmantelamiento por expolio y poniendo en situación de riesgo la supervivencia de este lugar de interés industrial.

Será a mediados de los años 50 del pasado siglo cuando las minas de Alquife adquieran su especificidad patrimonial a partir del desarrollo del plan de ordenación urbana para la realización de un pequeño poblado industrial. Este asentamiento, proyecto del arquitecto Ambrosio del Valle para la Compañia Andaluza de Minas, contaría con la construcción de un total de 90 viviendas, un hospital, dos escuelas, un cine de inverno, un casino y una capilla. A este programa se le añadirá posteriormente un economato, un cine de verano y una guardería.

La construcción de poblados industriales se reveló como una fórmula realmente idónea para la consecución de los objetivos paternalistas de las industrias. La atracción, el arraigo y la disciplina de los trabajadores serán los motores para el desarrollo de este fenómeno que, lejos de agotarse en los primeros años del siglo
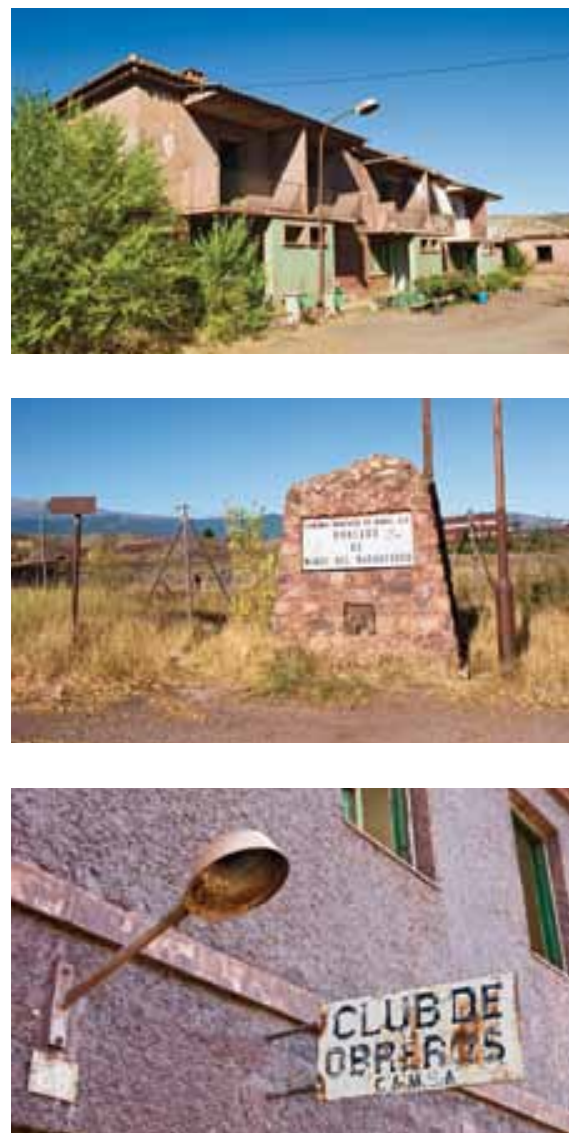

Poblado de trabajadores de las minas de Alquife (Granada)

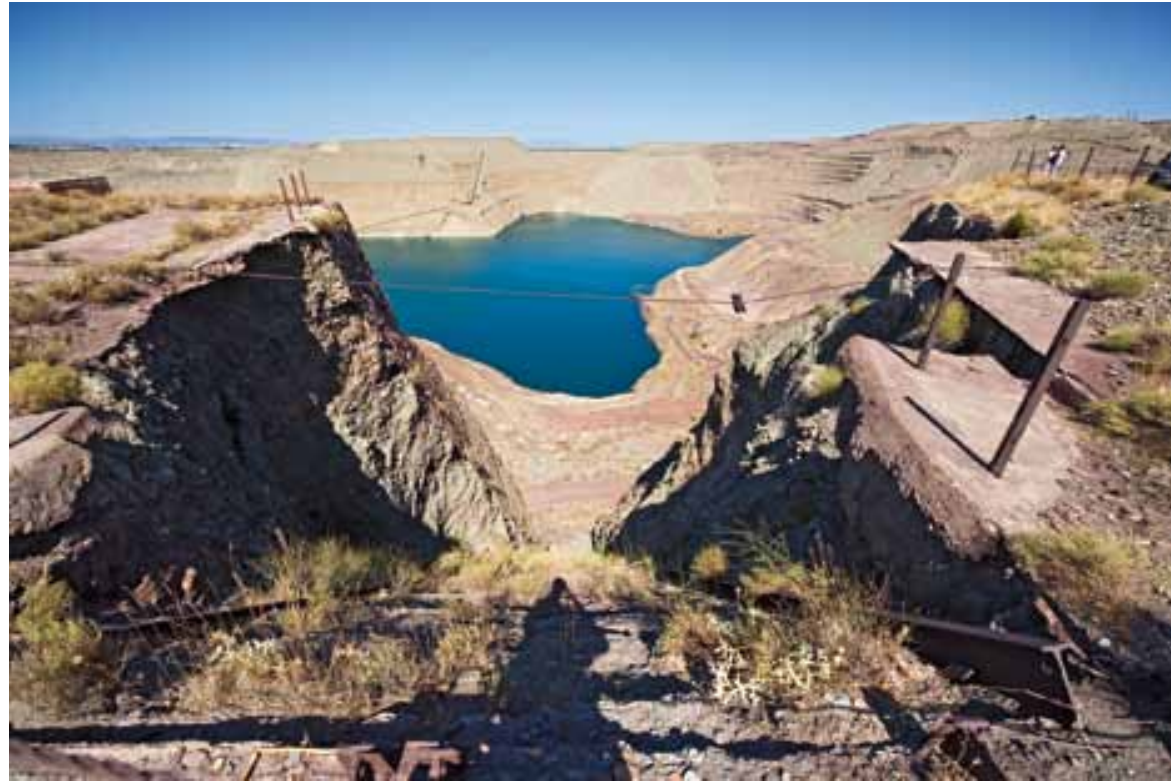

Minas de Alquife inundadas

$X X_{1}$ aflora en España con un inusitado vigor tras la guerra de 1936 y sobrevive en las etapas iniciales del desarrollismo de la década de los años sesenta. En el diseño de estos espacios física y socialmente pautados, marcados por una estricta segregación interna, la vivienda se presentará como un aspecto clave.

En atención a la categoría de los trabajadores de la mina: obreros, técnicos y directivos, se diseñaron, entre los años 1957 y 1962, dos núcleos residenciales situados al este de las instalaciones industriales. Para la construcción de este conjunto urbano moderno la compañía contaba con la ley de viviendas de renta limitada como instrumento juridico fundamental a través del cual se beneficiaba de bonificaciones tributarias, subvenciones y suministro preferente de material. La vivienda, unifamiliar pareada o aislada de una o dos alturas, fue reflejo del interés por la mejora en el confort de la residencia atendiendo a cuestiones como la disposición de las parcelas, la orientación de las estancias, la iluminación, la ventilación y la higiene. El diseño de la vivienda coexistió con el de los equipamientos, destinados a dotar a la población de los servicios necesarios para alcanzar mayores cuotas de bienestar social.

En este sentido, la vivienda, los equipamientos y el espacio público fueron objeto de una experiencia singular de adaptación de la arquitectura popular a los dictados de normalización que la modernidad imponía. Esta inquietud por la integración de los nuevos poblados, agrarios o industriales, en las corrientes vivas de la cultura contemporánea, se manifestará en España de forma ejemplar en las actuaciones de desarrollo rural promovidas por el Instituto Nacional de Colonización.

A diferencia de estos últimos, la existencia de los poblados mineros industriales no se explicaría sin la existencia previa tanto de las minas como de las ins- talaciones para su explotación y, sobre todo en este caso, de las antiguas viviendas para trabajadores de la compañia que constituyen el antecedente inmediato del actual poblado minero.

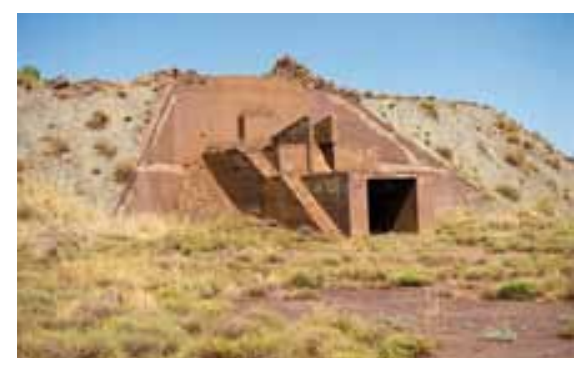

La construcción del poblado para los trabajadores de las minas de Alquife constituiría la pieza angular del proyecto general de saneamiento y modernización emprendido por la empresa, que se extendió también a la mejora en las instalaciones industriales. El parque minero destinado al tratamiento, almacenamiento y transporte del mineral así como a la dotación de varios servicios para los trabajadores, contaba con una planta para el lavado y el cribado del hierro (1972), una para su clasificación hidráulica y separación magnética (1984), una acopiadora o cinta transportadora, talleres, almacenes de herramientas, testigos y pólvora, vestuarios, oficinas, comedor y laboratorio. Contaba además con un cargadero de mineral situado junto a las vías de ferrocarril Alquife-GuadixAlmería, y una subestación eléctrica.

Estas instalaciones estaban puestas al servicio de las toneladas de mineral extraido principalmente de la corta, una de las mayores explotaciones a cielo abierto de Andalucia junto a la corta Atalaya de Riotinto en Huelva. Desde el cese de la actividad de la mina en el año 1996, esta gigantesca cantera de 1,5 km² de superficie y una profundidad aproximada de 225 
$m$ se encuentra inundada como consecuencia de la paralización del bombeo.

La declaración del complejo minero de Alquife como Bien de Interés Cultural, inscrito el 26 de julio de 2010, vino a dar reconocimiento a los valores de este conjunto urbano moderno y supuso en buena medida, la consecución del objetivo básico de toda protección patrimonial: el afianzamiento de la conciencia de identidad y cultura de un territorio. Sin embargo, transcurridos ya algunos meses desde su protección, la falta de salvaguarda y conservación del complejo minero en la actualidad plantea nuevos debates sobre el papel de las políticas públicas y de la sociedad para la garantía de dicho objetivo básico.

En esta tarea es necesario ver la oportunidad en aquellos casos donde más compleja es la labor de protección. Las herramientas clave para la consecución del objetivo básico siguen siendo, como en cualquier otra cuestión patrimonial, la investigación, que asegure un conocimiento preciso de los testimonios vivos de la industrialización en nuestro territorio; la difusión, que fomente la transmisión de sus valores a la sociedad y la demanda ciudadana de conservación; y la intervención, que salvaguarde los elementos que se encuentren en riesgo.

Sin embargo, este proceso de consolidación de la cultura de un territorio no se puede entender sin la participación activa de la ciudadanía y su interacción con los distintos niveles públicos y las organizaciones privadas. De esta manera, se podrá lograr una salvaguarda movida por una sociedad que reconoce en los restos de la industria una pieza indispensable para la construcción de su propia identidad y que demanda unas medidas de conservación adecuadas al valor de esta parte fundamental de su historia. Es así como podemos encontrar una oportunidad única para lograr la eficacia, calidad y la buena orientación de la intervención patrimonial.

El espacio urbano-industrial de Alquife representa una quimera de la modernidad andaluza, resultado de la superposición de diferentes etapas, que han llegado hasta nuestros dias como partes de una sola realidad, y reclama una atención singularizada. Depositario de una historia derivada de una forma de vida y de trabajo determinadas, este conjunto minero ha configurado una identidad colectiva en el territorio y constituye un patrimonio minero-industrial vivo, susceptible de seguir siendo explotado en función de las actuales concesiones extractivas, vivido y disfrutado por todos.

Marta Santofimia Albiñana

Centro de Documentación y Estudios del IAPH
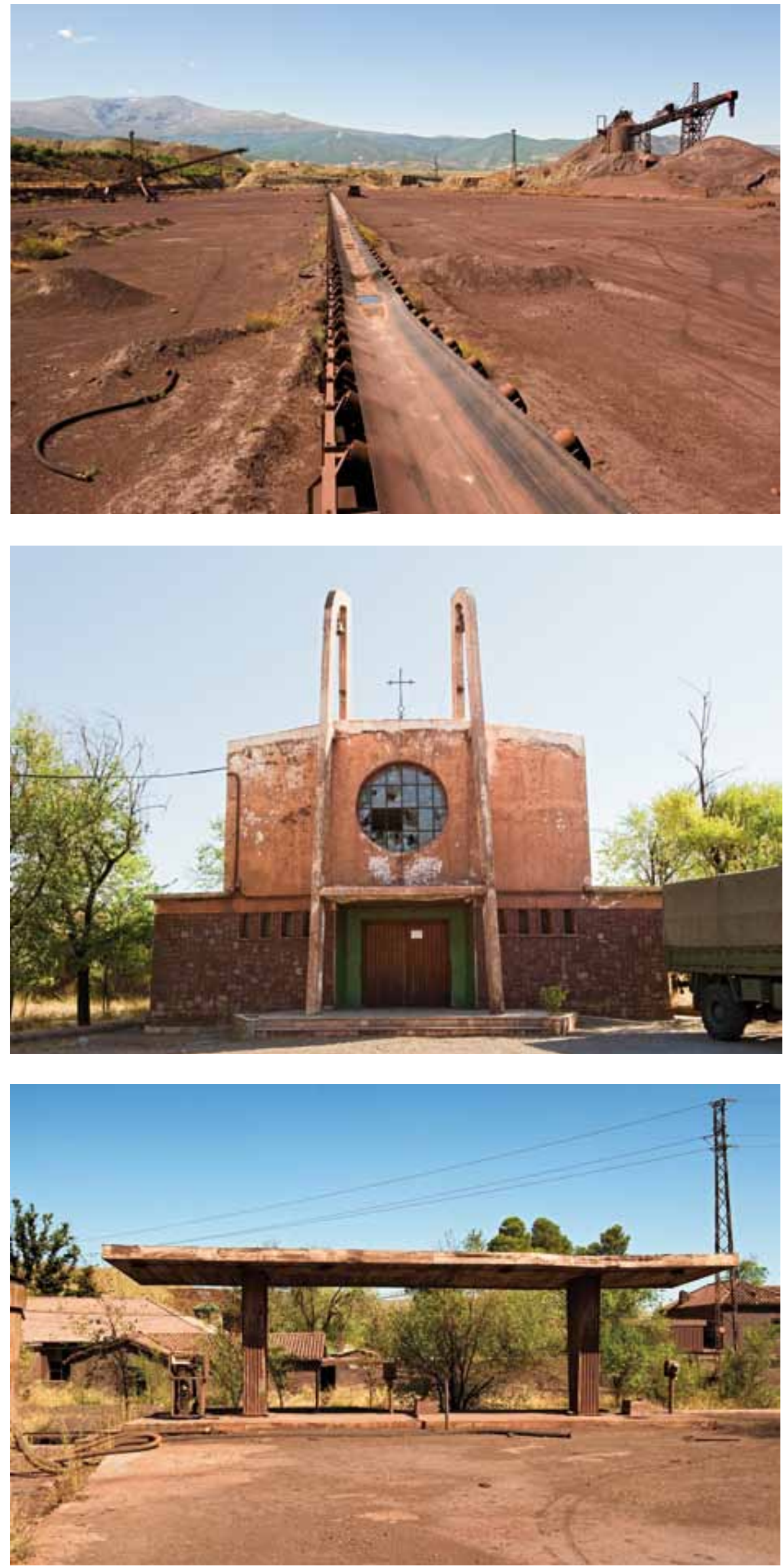

Complejo minero de Alquife. Fotos: Fondo Gráfico IAPH (Juan Carlos Cazalla) 